\title{
Inductive Heating Assisted-Catalytic Dehydrogenation of Tetralin as a Hydrogen Source for Downhole Catalytic Upgrading of Heavy Oil
}

\author{
Abarasi Hart ${ }^{1} \cdot$ Mohamed Adam $^{2} \cdot$ John P. Robinson ${ }^{2} \cdot$ Sean P. Rigby ${ }^{2} \cdot$ Joseph Wood $^{1}$ (D
}

Published online: 23 November 2019

(c) The Author(s) 2019

\begin{abstract}
The Toe-to-Heel Air Injection (THAI) combined with a catalytic add-on (CAPRI, CATalytic upgrading PRocess In-situ) have been a subject of investigation since 2002. The major challenges have been catalyst deactivation due to coke deposition and low temperatures $\left(\sim 300^{\circ} \mathrm{C}\right)$ of the mobilised hot oil flowing over the catalyst packing around the horizontal well. Tetralin has been used to suppress coke formation and also improve upgraded oil quality due to its hydrogen-donor capability. Herein, inductive heating (IH) incorporated to the horizontal production well is investigated as one means to resolve the temperature shortfall. The effect of reaction temperature on tetralin dehydrogenation and hydrogen evolution over $\mathrm{NiMo} /$ $\mathrm{Al}_{2} \mathrm{O}_{3}$ catalyst at $250-350{ }^{\circ} \mathrm{C}$, catalyst-to-steel ball ratio $(70 \% \mathrm{v} / \mathrm{v}), 18 \mathrm{bar}$ and $0.75 \mathrm{~h}^{-1}$ was investigated. As temperature increased from 250 to $350{ }^{\circ} \mathrm{C}$, tetralin conversion increased from 40 to $88 \%$ while liberated hydrogen increased from 0.36 to $0.88 \mathrm{~mol}$ based on $0.61 \mathrm{~mol}$ of tetralin used. The evolved hydrogen in situ hydrogenated unreacted tetralin to trans and cis-decalins with the selectivity of cis-decalin slightly more at $250{ }^{\circ} \mathrm{C}$ while at $300-350{ }^{\circ} \mathrm{C}$ trans-decalin showed superior selectivity. With IH the catalyst bed temperature was closer to the desired temperature $\left(300{ }^{\circ} \mathrm{C}\right)$ with a mean of $299.2{ }^{\circ} \mathrm{C}$ while conventional heating is $294.3^{\circ} \mathrm{C}$. This thermal advantage and the nonthermal effect from electromagnetic field under $\mathrm{IH}$ improved catalytic activity and reaction rate, though coke formation increased.
\end{abstract}

Keywords Inductive heating $\cdot$ Catalytic upgrading $\cdot$ Tetralin $\cdot$ Hydrogen

\section{Introduction}

Worldwide transportation energy consumption was forecast as 151 quadrillion Btu in 2040, which represents an increase of 44 quadrillion Btu from 2015 [1]. As the world's demand for transportation fuels is rising, securing adequate supply is the real challenge. The major source of supply, light crude oil, has peaked and is declining in reserves [2,3]. Heavy oil and bitumen hold about $70 \%$ of the world's oil reserves, estimated at 13 trillion barrels [3], which has shifted attention towards developing extraction and upgrading technologies for them. This is because under reservoir conditions, heavy oils cannot flow like light oil and, so resist flow toward the production well as they are highly-viscous and possess low

Joseph Wood

J.Wood@bham.ac.uk

1 School of Chemical Engineering, University of Birmingham, Edgbaston, Birmingham B15 2TT, UK

2 Faculty of Engineering, University of Nottingham, Nottingham NG7 2RD, UK
American Petroleum Institute (API) gravity. Hence, upon production, additional costs are incurred for pipeline transport and surface upgrading.

The commonly used extraction methods are steam injections such as cyclic steam stimulation and Steam Assisted Gravity Drainage (SAGD). However, alternatives include in situ combustion and Toe-to-Heel Air Injection (THAI) process. For simultaneous extraction and downhole upgrading of heavy oils, a catalytic add-on (CAPRI, CAtalytic upgrading PRocess In-situ) was combined with THAI [2, 4]. In this process, about $10-15 \%$ of the original oil in place is combusted and the developed combustion front advances from toe to heel of the horizontal production well through continuous air injection via a vertical injection well. The high thermal energy released from the combustion reaction between the oil and injected air increases the temperatures of the combustion front in the range of $400-700{ }^{\circ} \mathrm{C}$, which mobilizes the rest of the oil toward the horizontal production well aided by gravity [4]. As the mobilized hot oil ahead of the combustion front flows over the catalyst packing around the horizontal well additional downhole upgrading occurs 
[2-4]. Previous studies found that the actual temperature of the mobilized hot oil passing through the catalyst packing around the horizontal well in the THAI process may not exceed $300{ }^{\circ} \mathrm{C}[5,6]$. However, in other studies it was found that a temperature of about $425{ }^{\circ} \mathrm{C}$ is needed to maximise catalytic upgrading $[2,3,7,8]$. To achieve the needed $425{ }^{\circ} \mathrm{C}$ or more, inductive heating (IH) has been proposed in this study as a means to provide the additional heating required for optimum catalytic upgrading. IH has previously been integrated with a batch reactor in which paramagnetic nanoparticles such as iron coated with silica were used to convert electromagnetic field to heat for organic synthesis process [9]. Also, applied to fluidized bed system by co-fluidization of conductive particles which are chemically inert in order to heat the process [10]. Furthermore, IH has been incorporated with steam-assisted gravity drainage (SAGD) to expand the steam chamber and improve oil recovery [11]. With the aid of composite catalyst pellets consisting of a conductive component and a catalytic material $[12,13]$, or a mixed bed of catalyst and conducting susceptors [10], an inductive system can be applied to generate thermal energy inside the reactor. Herein, a laboratory-scale inductive heated reactor was developed, and a mixed bed of catalyst and chemically inert steel balls susceptors used to convert electromagnetic field into heat, which increases the temperature of the catalytic bed to the reaction temperatures. This is done with an emphasis on applications in THAI-CAPRI process for heavy oil recovery and in situ upgrading. The heat is generated rapidly in the area of interest; thus minimising heat lost, lowering energy costs, maintaining uniform temperature across the catalytic bed and ensuring controllability [10, 13].

Another challenge with in situ catalytic upgrading of heavy oils using THAI-CAPRI is large coke deposition on the catalyst results in rapid deactivation, bed plugging and low quality of upgraded oil $[14,15]$. Coke formation can be suppressed when the catalytic upgrading is carried out under a hydrogen rich environment [15]. The difficulty, safety and cost associated with transporting hydrogen gas itself into the reservoir have shifted attention to hydrogen-donor solvents such as polycyclic compounds (i.e., cyclohexane, decalin and tetralin) [16]. These organic liquids potentially store and transport hydrogen in a safer and less challenging manner when compared to external transport of hydrogen gas itself into the reservoir. Also, they can easily be injected into the reservoir using either the vertical injection or horizontal production wells of the THAI-CAPRI process. These polycyclic compounds can hydrogenate-dehydrogenate in the upgrading mixture, and the evolved hydrogen has been found to improve the quality of upgraded oil and minimise coke formation by halting polymerisation of free radicals from cracked heavy molecules. The dehydrogenation of tetralin to naphthalene can be used as a hydrogen source to promote in situ hydrocracking and hydrogenation reactions in the catalytic addon (CAPRI) to THAI. Hart et al. [16] reported that the use of cyclohexane as hydrogen-donor solvent for downhole catalytic upgrading of heavy oil suppressed coke formation. Many studies have reported the use of tetralin as $\mathrm{H}$-donor solvent $[14,17,18]$, and the findings showed that coke formation is suppressed and upgraded oil quality improved. However, studies on the quantification of liberated hydrogen from tetralin are very limited even though the mechanism of hydrogen evolution through dehydrogenation of tetralin to naphthalene is well-known. These polycyclic compounds have shown the ability to suppress coke formation which is usually attributed to the participation of the evolved hydrogen in the upgrading process.

The dehydrogenation of tetralin to liberate hydrogen and produce naphthalene is faced with two challenges. The first is that dehydrogenation is an endothermic reaction that requires high temperature, and the temperature of the hot oil passing over the catalyst bed in the THAI-CAPRI is in the range of only 100 to $300{ }^{\circ} \mathrm{C}$ [6], which is non-uniform and also below $425^{\circ} \mathrm{C}$ needed for effective catalytic upgrading. The other is that the produced naphthalene will compete with the heavy oil molecules for adsorption on the catalyst active sites $[19,20]$. Since the catalyst bed under IH functions as a heat generator, the first challenge can be addressed unlike conventional heating $(\mathrm{CH})$ system where the catalyst bed acts as a heat sink. The catalytic dehydrogenation of tetralin to naphthalene is commonly performed over Pd or Pt supported catalyst at high temperature [21-23]. However, $\mathrm{Pd}$ or Pt cannot withstand the sulphur content in heavy oil. Hence, transition metals such as $\mathrm{Ni}$, Co and Mo supported on alumina and/or silica are commonly used in catalytic upgrading of heavy oil and were used in this study [24, 25]. In this study, a laboratory-scale inductive heated reactor to be combined with THAI-CAPRI process for heavy oil recovery and in situ upgrading was developed. Heat was generated inside the mixed bed of catalyst $\left(\mathrm{NiMo} / \mathrm{Al}_{2} \mathrm{O}_{3}\right)$ pellets and steel balls of size $3 \mathrm{~mm}$ which convert electromagnetic field into heat. It has been demonstrated that the mixture of $\mathrm{NiMo} / \mathrm{Al}_{2} \mathrm{O}_{3}$ catalyst and steel balls (catalyst-to-steel balls ratio, CTSBR 70\% v/v) inside the CAPRI reactor can rapidly heat the catalyst to $425^{\circ} \mathrm{C}$ in about $25 \mathrm{~min}$ and enhance catalytic transformation compare to $\mathrm{CH}$. The amount of hydrogen obtainable from tetralin as hydrogen-donor solvent for catalytic upgrading of heavy oil using hydrotreating (HDT) catalyst $\mathrm{NiMo} / \mathrm{Al}_{2} \mathrm{O}_{3}$ was experimentally verified. The effect of reaction temperature on hydrogen evolution was examined. Furthermore, a comparative study was carried out on tetralin conversion and hydrogen evolution when the mixed bed of catalyst was heated inductively with steel balls and conventionally at varying reaction temperatures. First-order kinetics and a plug flow model were used to estimate the 
apparent rate constant and apparent activation energy of the reaction in both inductive and conventional heated systems.

\section{Experimental}

\subsection{Materials}

Commercial HDT catalyst $\mathrm{NiMo} / \mathrm{Al}_{2} \mathrm{O}_{3}$ quadra-lobe shaped (Akzo-Nobel) was used. The tetralin (99.5\% purity) used in this study was purchased from Sigma Aldrich, UK and $n$-hexadecane (99\%, Alfa Aesar, UK) as solvent. $80 \mathrm{~g}$ of tetralin was added to $1 \mathrm{~L}$ of $n$-hexadecane stirred for $2 \mathrm{~h}$ by magnetic stirrer to form a solution used for the reaction.

\subsection{CAPRI Reactor}

The inductive heated CAPRI reactor to be combined with the horizontal production well of the THAI process was replicated by a fixed-bed reactor, which comprises of a quartz glass tube (length $440 \mathrm{~mm}$ and diameters $20 \mathrm{~mm}$ i.d., $40 \mathrm{~mm}$ o.d.) where an induction coil was wrapped around it. The schematic diagram of the experimental reactor is shown in Fig. 1. The bed of catalyst was a mixture of $\mathrm{NiMo} / \mathrm{Al}_{2} \mathrm{O}_{3}$ pellets and steels balls of $3 \mathrm{~mm}$. The steel balls function as susceptors that convert electromagnetic field into heat to inductively heat the catalyst bed. The top and bottom of the bed was occupied by chemically inert glass beads of size $5 \mathrm{~mm}$. A thermocouple (type k) was inserted from the bottom to the centre of the catalytic bed to measure temperature. The experiment was carried out at the percolation threshold of $70 \%(\mathrm{v} / \mathrm{v})$ CTSBR (this is the minimum amount of steel balls required to achieve a thermal conducting pathway throughout the bed), pressure 18 barg, LHSV $0.75 \mathrm{~h}^{-1}$, temperature $250-380{ }^{\circ} \mathrm{C}$ and gas flow rate of $200 \mathrm{~mL} \mathrm{~min}^{-1}$ $\left(\mathrm{N}_{2}\right)$. The liquid reactant was pumped through using a HPLC pump, preheated to $190{ }^{\circ} \mathrm{C}$ and introduced in a downward flow mode into the reactor. This simulates the mobile oil zone and the gravity drainage of the hot oil passing over the catalyst bed around the horizontal well of the THAI process. The dehydrogenation reaction was carried out under a nitrogen environment, and the pressure inside the reactor was controlled using a back pressure regulator. An identical experimental configuration was used for the $\mathrm{CH}$ experiment as control in which the heat is generated by an external electrical furnace. Before the start of experiment, the catalyst was reduced in a hydrogen gas atmosphere at a temperature of $300{ }^{\circ} \mathrm{C}$, pressure of 5 bar and flowrate of $20 \mathrm{~mL} \mathrm{~min}^{-1}$.

\subsection{Analytical}

The liquid product was analysed using a FID equipped gas chromatograph (GC) $6890 \mathrm{~N}$ and a capillary column HP-5 $(30 \mathrm{~m} \times 0.320 \mathrm{~mm} \times 0.25 \mu \mathrm{m})$. The catalyst surface area, pore volume and size were determined by nitrogen adsorption technique using Micrometritics Analytical Instrument ASAP® 2010, using the Brunauer-Emmett-Teller (BET) and Barrett-Joyner-Halenda (BJH) equations according to ASTM C1274. Bruker AXS GmbH (D8 Advanced XRD, Karlsruhe, Germany) was used to collect the X-ray diffraction (XRD) data of the catalyst using $\mathrm{Cu} \mathrm{K} \alpha$ radiation from 10 to $80^{\circ} 2 \theta$ and a step width size of $0.025^{\circ}$. Consequently, Hitachi TM3030Plus tabletop scanning electron microscope equipped energy dispersive X-ray spectroscopy (EDS) was used to examine the morphology of catalyst and quantify the elemental composition. Micromeritics AutoChem II 2920 analyser was used to determine the number and the strength of the catalyst acid sites through temperature programmed desorption using tert-butylamine $\left[\left(\mathrm{CH}_{3}\right)_{3} \mathrm{CNH}_{2}\right]$. The coke deposited on the catalyst after reaction was determined using a thermogravimetric analyser, TGA (TG 209 F1 Iris $®$ instrument, Netzsch-Geratebau $\mathrm{GmbH}$ ) under air atmosphere with
Fig. 1 Inductive heated-catalytic reactor

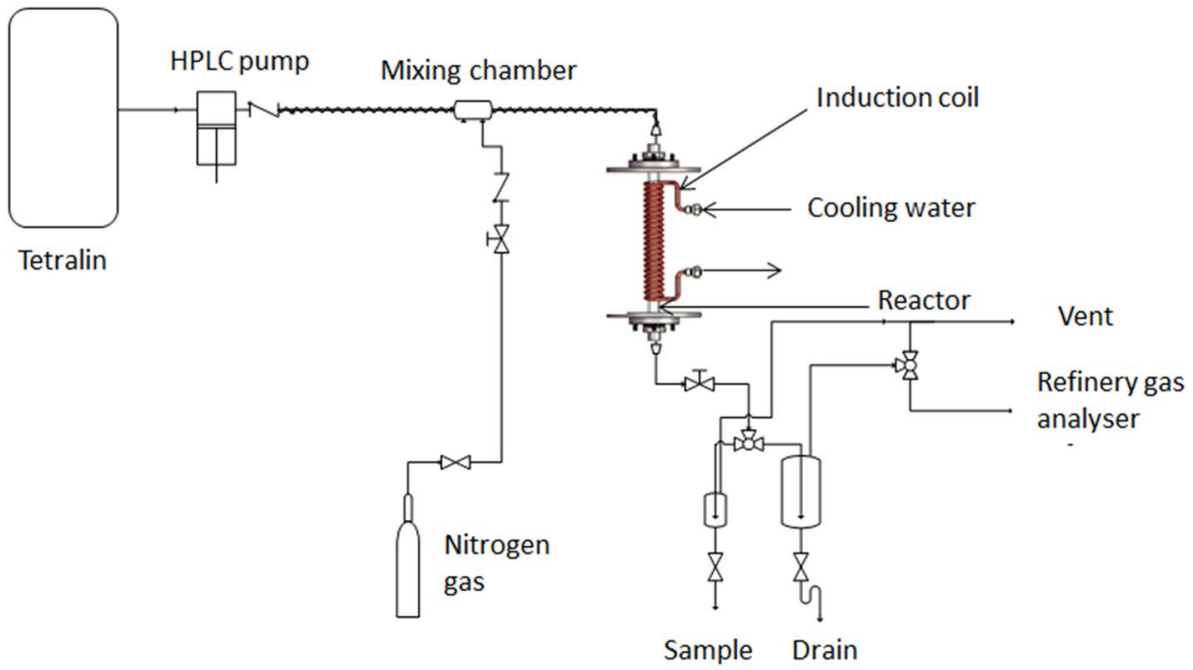


flowrate $50 \mathrm{~mL} \mathrm{~min}^{-1}$, ramp temperature 25 to $900{ }^{\circ} \mathrm{C}$ step increase $10^{\circ} \mathrm{Cmin}^{-1}$ and held at $900{ }^{\circ} \mathrm{C}$ for $8 \mathrm{~min}$. The gaseous product was analysed online using Agilent 7890A GC configured as a refinery gas analyzer.

\section{Results and Discussion}

A flowchart of the tetralin dehydrogenation is shown in reaction Scheme 1. The amount of hydrogen liberated from tetralin due to dehydrogenation to naphthalene, the conversion of tetralin, and the respective selectivity of naphthalene, trans and cis-decalins, and fixed-bed reaction kinetic are presented and discussion in Sects. 3.1 to 3.4. The effect of electromagnetic field and the thermal advantage due to $\mathrm{IH}$ on the catalyst performance evaluated against $\mathrm{CH}$ is presented and discussed in Sect. 3.5.

The conversion of tetralin and the respective selectivity of the dehydrogenation products are defined by the equations.

The conversion of tetralin:

Conversion $=\frac{\mathrm{C}_{\text {Tetralin }}^{0}-\mathrm{C}_{\text {Tetralin }}}{\mathrm{C}_{\text {Tetralin }}^{0}} \times 100 \%$.

The selectivity of compound i:

Selectivity $\left(\mathrm{S}_{\mathrm{i}}\right)=\frac{\mathrm{C}_{\mathrm{i}}}{\sum_{\mathrm{i}=1}^{\mathrm{n}} \mathrm{C}_{\mathrm{i}}} \times 100 \%$,

where $\mathrm{C}_{\text {Tetralin }}^{0}, \mathrm{C}_{\text {Tetralin }}$ are the initial and final concentration of tetralin and $\mathrm{C}_{\mathrm{i}}$ is the concentration for compound $\mathrm{i}$.

\subsection{Catalyst Characterization}

The physicochemical properties of the $\mathrm{NiMo} / \mathrm{Al}_{2} \mathrm{O}_{3}$ catalyst used are shown in Table 1. Figure 2 shows the nitrogen adsorption-desorption isotherm (a) and the XRD (b). The nitrogen adsorption-desorption isotherm curve (Fig. 2a) shows a big hysteresis loop between the adsorption and desorption isotherms, signifying type IV isotherm and mesoporous characteristics. The XRD pattern reveals two prominent peaks of cubic $\gamma-\mathrm{Al}_{2} \mathrm{O}_{3}$ at $46^{\circ}$ and $67^{\circ}$ (Fig. 2b). The presence of peaks at $2 \theta$ of $37.3^{\circ}$ indicates common $\mathrm{Ni}$
Table 1 Physicochemical properties of $\mathrm{NiMo} / \mathrm{Al}_{2} \mathrm{O}_{3}$ catalyst

\begin{tabular}{ll}
\hline Parameter & Values \\
\hline Specific surface area $\left(\mathrm{m}^{2} \mathrm{~g}^{-1}\right)$ & 237.74 \\
Pore volume $\left(\mathrm{cm}^{3} \mathrm{~g}^{-1}\right)$ & 0.57 \\
Pore diameter $(\mathrm{nm})$ & 8.8 \\
$\mathrm{Ni}(\mathrm{wt} \%)$ & 7 \\
Mo (wt\%) & 21 \\
Weak acid site at $280{ }^{\circ} \mathrm{C}\left[\mathrm{mmol}\right.$ adsorbed $\left.\left(\mathrm{CH}_{3}\right)_{3} \mathrm{CNH}_{2} \mathrm{~g}^{-1}\right]$ & 0.62 \\
Strong acid site at $480{ }^{\circ} \mathrm{C}\left[\mathrm{mmol}\right.$ adsorbed $\left.\left(\mathrm{CH}_{3}\right)_{3} \mathrm{CNH}_{2} \mathrm{~g}^{-1}\right]$ & 0.12 \\
\hline
\end{tabular}

oxides ( $\mathrm{NiO}$ and $\left.\mathrm{Ni}_{2} \mathrm{O}_{3}\right)$. The small peak that appears at $33.6^{\circ}$ can be attributed to $\mathrm{MoO}_{3}$.

The SEM micrograph and EDS of the catalyst are shown in Fig. 3, displaying the surface morphology of the NiMo/ $\mathrm{Al}_{2} \mathrm{O}_{3}$ catalyst. The active phase species $\mathrm{Ni}$ and $\mathrm{Mo}$ are welldispersed on the surface of the alumina support as shown in the elemental mapping (Fig. 3c, d) with 7.3\% Ni and 20.5\% Mo, which implies the ratio of Ni to Mo is approximately $1: 3$. This ratio of promoter $(\mathrm{Ni})$ to active element $(\mathrm{Mo})$ is within a typical HDT catalyst.

\subsection{Catalyst Bed Temperature Profiles}

The design of the inductive heated reactor makes it technically challenging to incorporate an infrared radiation thermometer to measure the temperature of the catalytic bed. However, it has been reported that the interference of electromagnetic field with the thermocouple can be significantly reduced by shielding for a frequency of $50 \mathrm{~Hz}$ [26]. The measured temperature profiles of the catalyst bed for different CTSBR ranging from 30 to $70 \%(\mathrm{v} / \mathrm{v}$ ) and the influence of magnetic field on the thermocouple reading are shown in Fig. 4. The temperature rose steeply to the desired reaction temperature in all cases, except for $70 \%$ (v/v). Since steel balls act as susceptors of electromagnetic fields and current, it is expected that the higher amount of steel balls would lead to higher heating rate due to increase interaction with the magnetic field. Hence, the volume of the bed $\left(80 \mathrm{~cm}^{3}\right)$ heats up more slowly as the amount of catalyst increases from 30 to $70 \%(\mathrm{v} / \mathrm{v})$. This is because the catalyst is non-conductive and therefore has
Scheme 1 Flowchart of tetralin dehydrogenation to liberate hydrogen and produce naphthalene

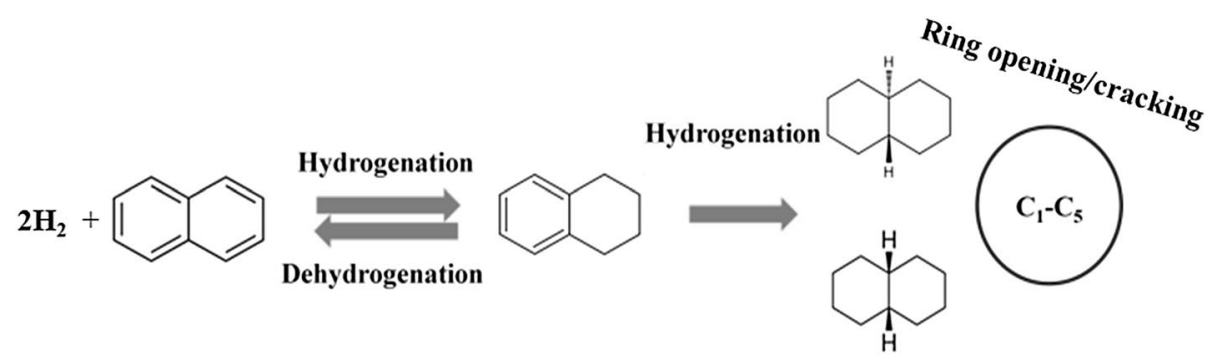



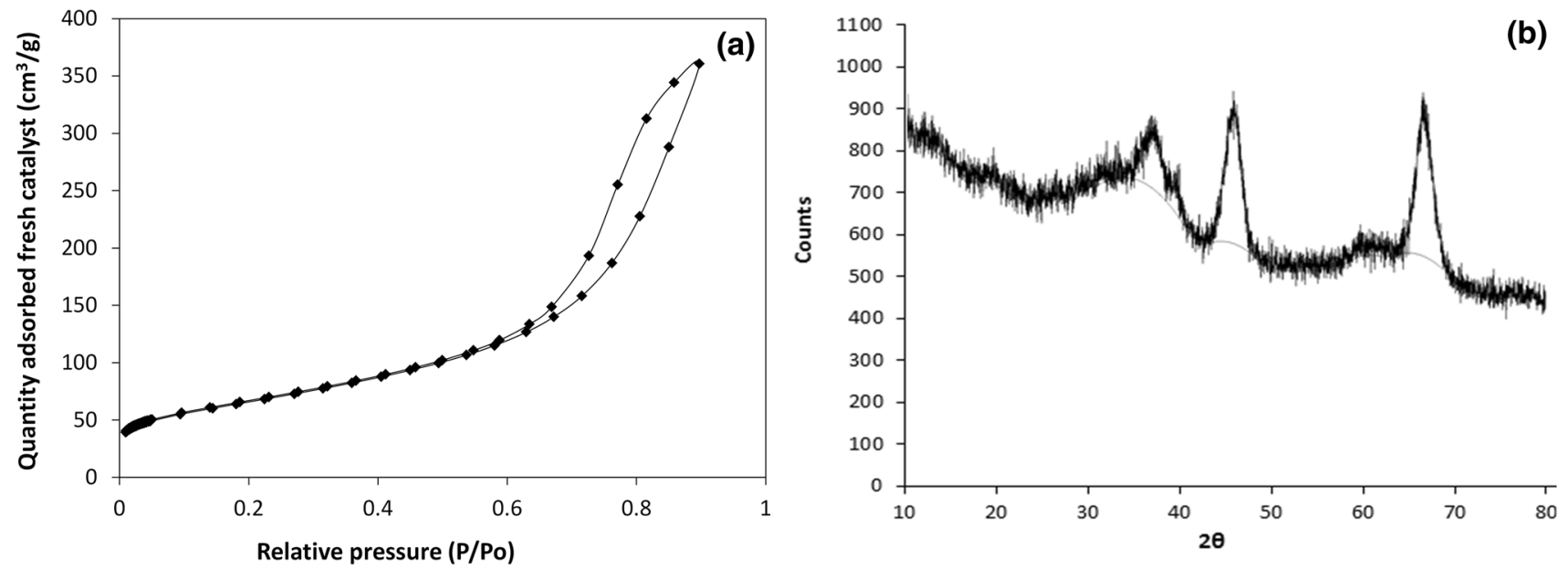

Fig. 2 Catalyst characteristics. a Nitrogen adsorption-desorption isotherm and $\mathbf{b}$ XRD pattern
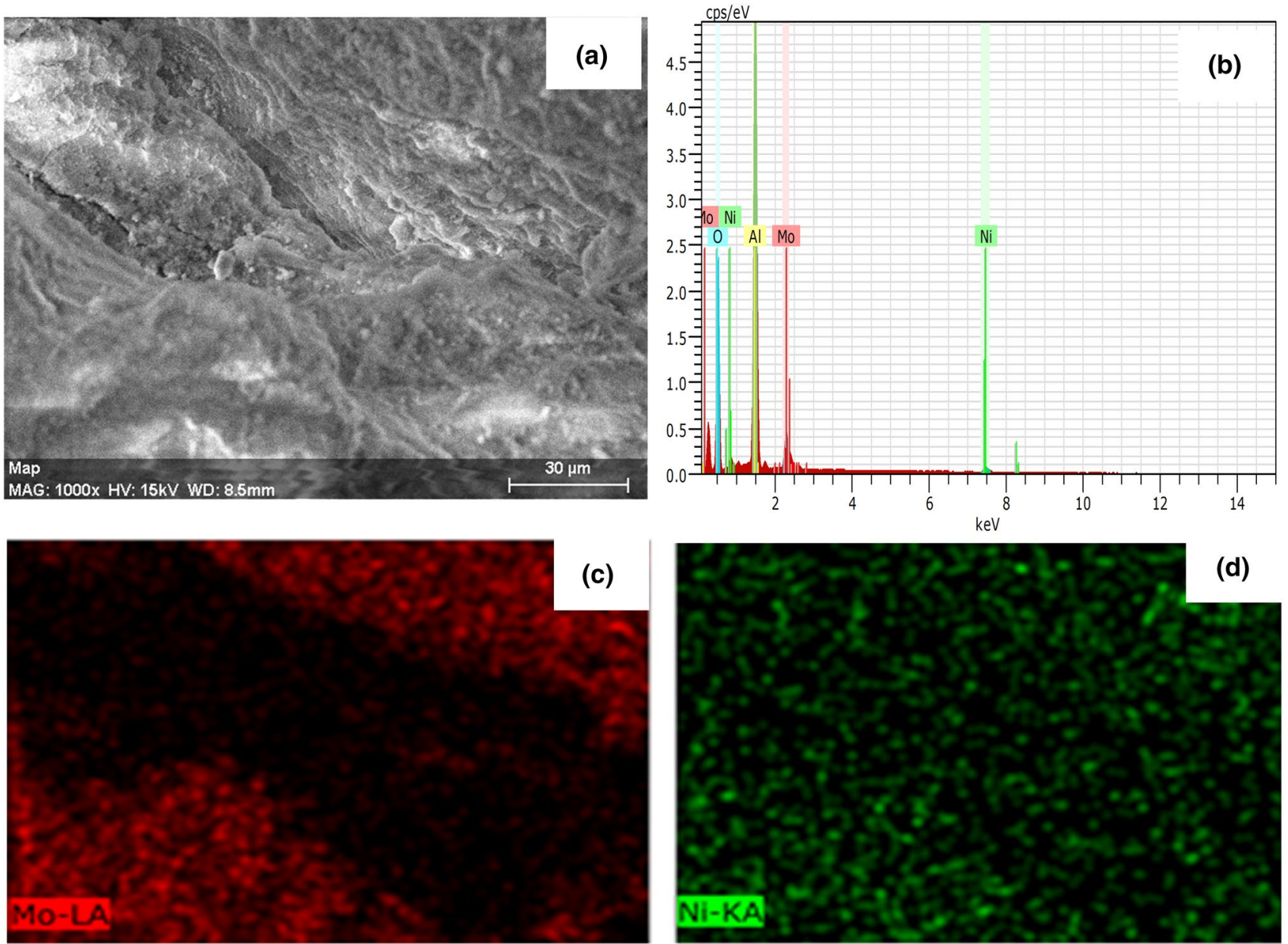

Fig. $3 \mathrm{NiMo} / \mathrm{Al}_{2} \mathrm{O}_{3}$ catalyst morphology. a SEM micrograph, b EDS, c Mo metal mapping and $\mathbf{d}$ Ni metal mapping

weak interaction with the electromagnetic fields. Hence, at CTSBR of $70 \%(\mathrm{v} / \mathrm{v})$, it is clear that the impact of the electromagnetic field upon the measured temperature by the thermocouple is greatly minimized due to the protection of the surrounding non-conducting catalyst, the thick quartz glass tube ( $20 \mathrm{~mm}$ i.d., $40 \mathrm{~mm}$ o.d.) and the size of the thermocouple probe $(1 \mathrm{~mm})$. At $35 \mathrm{kHz}$ experimental frequency and $70 \%$ CTSBR, the interaction of the magnetic field with 
the thermocouple was tested (Fig. 4b). Henkel et al. [27] measured the temperature of a packed bed reactor inductively heated for pyrolysis of biomass using k-type thermocouple, once the reactor achieved the target temperature, the induction heater was switched off and the thermocouple (k-type) inserted immediately to measure the steady state temperature. In the same vein, the catalytic bed was heated inductively to $124{ }^{\circ} \mathrm{C}$ for CTSBR of $70 \%$, and the induction heater was turned off, while the installed thermocouple response and that of the inserted thermocouple from the top were observed as shown in Fig. 4b. It can be observed that when the eddy current and magnetic field effects were eliminated by turning off the induction heater while still monitoring the temperature of the catalytic bed, the installed thermocouple maintained $124^{\circ} \mathrm{C}$ for $82 \mathrm{~s}$, while the inserted thermocouple started off from $125^{\circ} \mathrm{C}$, dropped to $124^{\circ} \mathrm{C}$ in $25 \mathrm{~s}$ and maintained this temperature for $70 \mathrm{~s}$ before a gradual drop in measured temperature was noticed (Fig. 4b). The difference between the measured temperature by the installed and the inserted thermocouples is about $1{ }^{\circ} \mathrm{C}$. This suggests that the sensitivity of the thermocouple to the magnetic field is significantly reduced at 70\% CTSBR in addition to the non-conducting shield provided by the thick $(10 \mathrm{~mm})$ quartz glass tube and the distance $(22 \mathrm{~mm})$ of the thermocouple from the induction coil. Additionally, the power of the induction heater is adjusted by a temperature controller which design includes a signal filtering and an isolator so that there was no current path to ground. While the temperature of the catalyst pellets was $124{ }^{\circ} \mathrm{C}$, the steel balls was $190^{\circ} \mathrm{C}$ which means the major heat transfer mode is conduction due to intimate contact between them.
The measured temperature by the thermocouple is approximately that of the heated catalytic bed, the difference between $60 \%$ and $70 \%$ (v/v) catalyst/steel ratio affirmed this observation. Hence, the measured temperature is the heating of the steel balls majorly. When the steel balls are packed with the catalyst, they create a thermal conducting network. Therefore, the significant difference in heating rate between $60 \%$ and $70 \%(\mathrm{v} / \mathrm{v})$ can be attributed to the percolation threshold for random sphere packing in $3 \mathrm{D}$ which is about 0.3. This means that the steel balls will form a percolating cluster and connectivity across the packed bed above $30 \%$ fractional occupancy and thus allow thermal conduction across the steel balls majorly.

\subsection{Conversion, Selectivity and Liberated Hydrogen}

The material balance of the system showed that at $350{ }^{\circ} \mathrm{C}$, the liquid (i.e., naphthalene, tetralin, trans and cis decalins) account for about $94.4 \mathrm{wt} \%$ and the remainder $5.6 \mathrm{wt} \%$ represent deposited coke on the catalyst and the gaseous products. The active metals (i.e., Ni and Mo) are responsible for hydrogenation/dehydrogenation while the acid sites of the alumina support induce catalytic cracking [3, 15]. Figure 5 shows the conversion of tetralin, produced hydrogen and the respective selectivity toward naphthalene and trans/cis-decalin from the dehydrogenation of tetralin at 250,300 and $350{ }^{\circ} \mathrm{C}$. On the graph, the primary vertical axis shows the conversion of tetralin and the selectivity of naphthalene while the secondary vertical axis indicates the selectivity of trans and cis-decalin. At all reaction temperatures investigated, tetralin conversion increases steeply with time-on-stream and plateaus within $100 \mathrm{~min}$ and remained
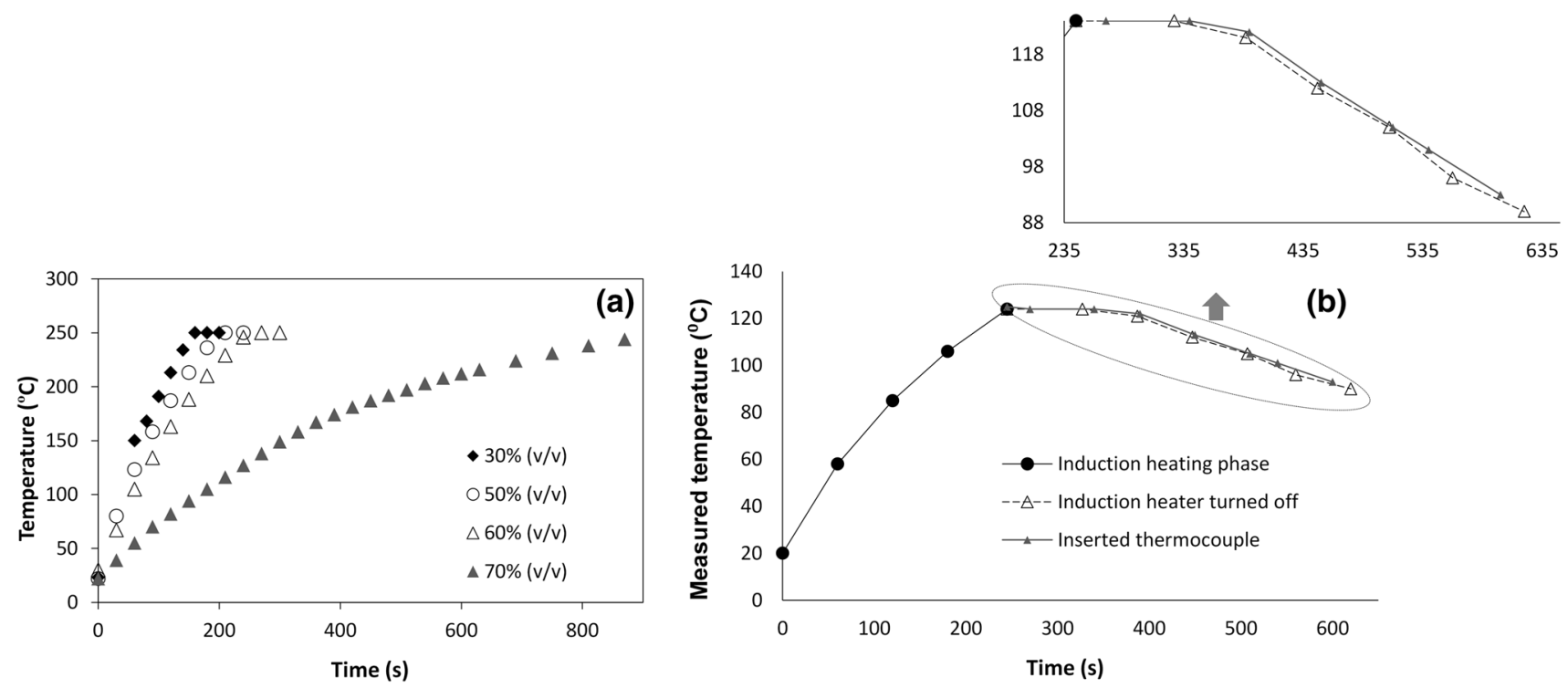

Fig. 4 Catalyst bed temperature $\mathbf{a}$ as a function of CTSBR (v/v) and $\mathbf{b}$ the influence of magnetic field and eddy current on the temperature reading of the thermocouple at $70 \%$ CTSBR 

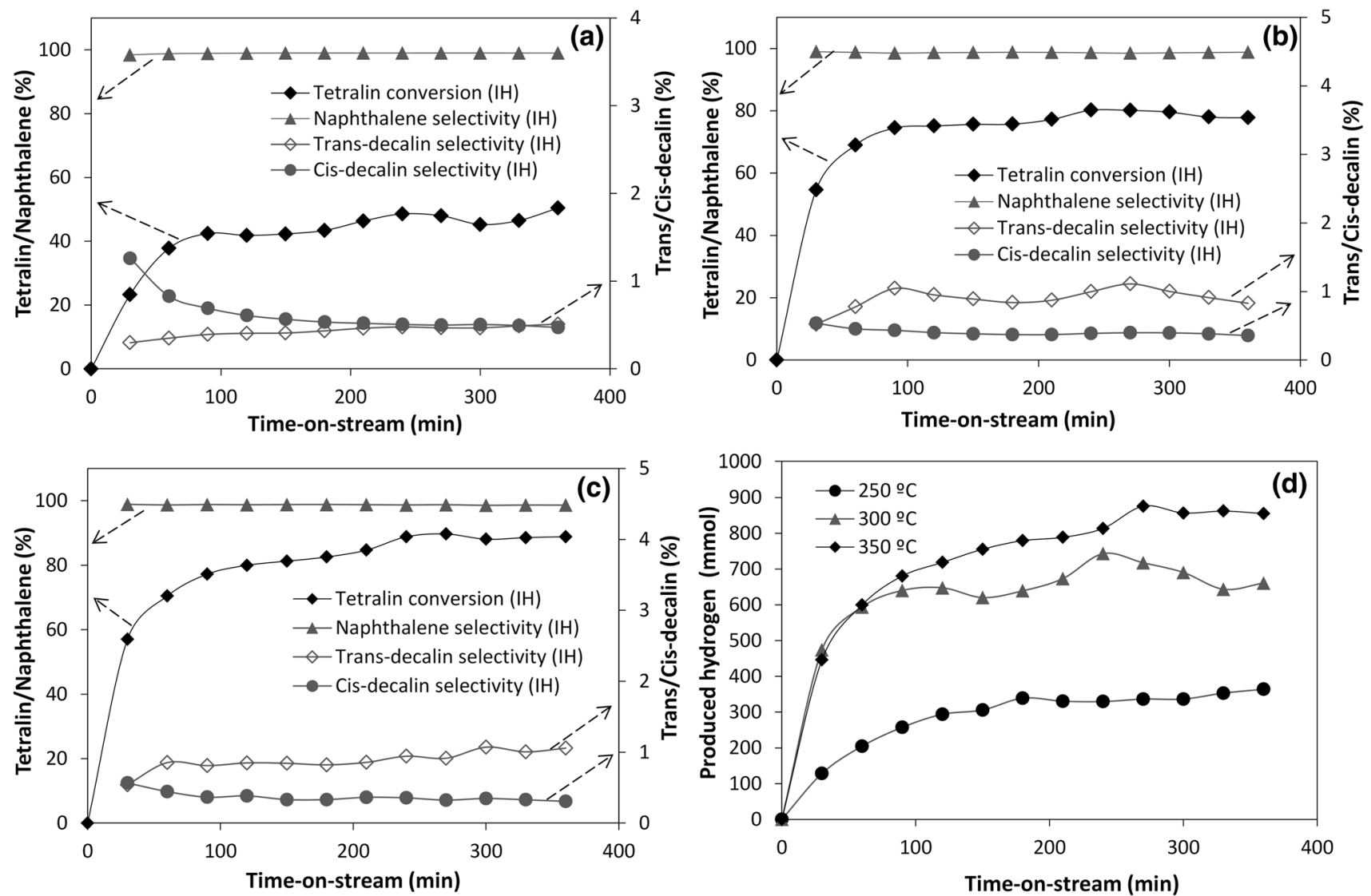

Fig. 5 Tetralin dehydrogenation under induction heating at a $250{ }^{\circ} \mathrm{C}, \mathbf{b} 300{ }^{\circ} \mathrm{C}, \mathbf{c} 350{ }^{\circ} \mathrm{C}$ and d produced hydrogen at pressure 18 barg, LHSV $0.75 \mathrm{~h}^{-1}, \mathrm{CTSBR} 70 \% \mathrm{v} / \mathrm{v}$ and gas flow rate of $200 \mathrm{~mL} \mathrm{~min}^{-1}\left(\mathrm{~N}_{2}\right)$

plateaued throughout the experiment, which indicates sustained catalyst activity. The observed early increase in conversion of tetralin to $100 \mathrm{~min}$ at all reaction temperatures investigated is as a result of catalyst start up effect, and can be attributed to the time required for steady state to be achieved in the reactor which includes time required for effective catalyst wetting and diffusion of reactants into and products out of the catalyst pore structure. The mean conversions of tetralin are as follows $43 \%\left(250{ }^{\circ} \mathrm{C}\right), 74.8 \%$ $\left(300{ }^{\circ} \mathrm{C}\right)$ and $81.5 \%\left(350{ }^{\circ} \mathrm{C}\right)$, respectively. Thermodynamically, high temperature is necessary to provide sufficient thermal energy for this endothermic reaction; hence, the conversion of tetralin via dehydrogenation to naphthalene and hydrogen liberation increased as temperature increased from 250 to $350{ }^{\circ} \mathrm{C}$. Chen et al. [20] observed a similar trend in tetralin conversion against time-on-stream and as reaction temperature increase. As expected, the endothermic nature of tetralin dehydrogenation process is favoured with increasing temperature.

The major product of the dehydrogenation reaction is naphthalene with selectivity of approximately $98 \%$ for all reaction temperatures investigated. The selectivity of cisdecalin is slightly more over the early minutes of experiment at $250{ }^{\circ} \mathrm{C}$. However, with time-on-stream, the ratio of cis to trans-decalin changes from 2.4:1 to $1: 1$ while at $300-350{ }^{\circ} \mathrm{C}$ trans-decalin showed superior selectivity than cis-decalin (ratio of 1:2). This trend is due to the instability of cis-decalin and its isomerisation to a more thermally stable transdecalin at high temperatures.

The formation of cis and trans decalins in the dehydrogenation of tetralin is an indication of the hydrogenation reaction promoted by the evolved hydrogen mainly due to naphthalene formation. The amount of decalin produced is very small, when compared to naphthalene produced, because of the small contact time remaining after naphthalene and hydrogen have been formed. The evolved hydrogen hydrogenates some residual tetralin, under the prevailing pressure, as its trickles down the catalyst bed. The reaction is also dependent on the prevailing partial pressure of hydrogen within the reactor. Additionally, the hydrogenation of tetralin to decalin is an exothermic one which is thermodynamically unfavourable at high reaction temperatures.

The evolved hydrogen produced from tetralin dehydrogenation was estimated from the amount of naphthalene produced excluding dialin (1,2-dihydronaphthalene) product (based on reaction Scheme 1, tetralin $=$ naphthalene $+2 \mathrm{H}_{2}$ 
and excluding teralin $=$ dialin $+\mathrm{H}_{2}$ ). Figure $5 \mathrm{~d}$ shows the hydrogen production against time-on-stream over $\mathrm{NiMo} /$ $\mathrm{Al}_{2} \mathrm{O}_{3}$ catalyst at 250,300 and $350^{\circ} \mathrm{C}$. The liberated hydrogen over the catalyst increases with time-on-stream and reaction temperature. The mean amounts of liberated hydrogen gas at the respective reaction temperatures are as follows $298.4 \mathrm{mmol}\left(250^{\circ} \mathrm{C}\right), 645.3 \mathrm{mmol}\left(300{ }^{\circ} \mathrm{C}\right)$ and $752.6 \mathrm{mmol}$ $\left(350{ }^{\circ} \mathrm{C}\right)$. An increase in the optimum amount of liberated hydrogen from 360 to $876 \mathrm{mmol}$ can be observed at $350{ }^{\circ} \mathrm{C}$. On the other hand, the amount of tetralin converted at each reaction temperature ranges from 141 to $305 \mathrm{mmol}$ $\left(250{ }^{\circ} \mathrm{C}\right), 330$ to $485 \mathrm{mmol}\left(300{ }^{\circ} \mathrm{C}\right)$ and 345 to $543 \mathrm{mmol}$ $\left(350{ }^{\circ} \mathrm{C}\right)$ relative to $605 \mathrm{mmol}$ of tetralin feedstock. The corresponding amounts of decalins produced are thus; at $250{ }^{\circ} \mathrm{C}$ (trans: $0.54-2.6 \mathrm{mmol}$, cis: $2.3-2.5 \mathrm{mmol}$ ), $300{ }^{\circ} \mathrm{C}$ (trans: $3.4-7.3 \mathrm{mmol}$, cis: $2-3.5 \mathrm{mmol}$ ) and $350{ }^{\circ} \mathrm{C}$ (trans: 1-10 mmol, cis: $3.65-5 \mathrm{mmol}$ ), respectively. This suggests that in situ hydrogenation of tetralin by the liberated hydrogen gas is negligible compared with the extent of dehydrogenation to naphthalene. This is because of temperature increase and limited hydrogen gas favours the dehydrogenation of tetralin to naphthalene as shown in Fig. 5a-c. Additionally, once tetralin dehydrogenate to hydrogen and naphthalene, the contact time between the hydrogen and the residual tetralin is insufficient to ensure reasonable conversion to trans and cis decalins in a fixed-bed continuous process.

The analysis of the gaseous product from the reaction showed the presence of $13.8 \mathrm{vol} \%\left(250{ }^{\circ} \mathrm{C}\right), 20.2 \mathrm{vol} \%$ $\left(300{ }^{\circ} \mathrm{C}\right)$ and 37.6 vol\% $\left(350{ }^{\circ} \mathrm{C}\right)$ hydrogen. Most of this hydrogen is due to the formation of naphthalene from tetralin (selectivity of 98\%) as only a negligible amount of 1,2-dihydronaphthalene was observed from the liquid product analysis. This evolved hydrogen under catalytic upgrading of heavy oil with tetralin as $\mathrm{H}$-donor can promote hydrocracking and hydrogenation reactions to stabilise free hydrocarbon radicals. The formation of trans and cis-decalins in the liquid product affirmed the occurrence of the hydrogenation reaction due to the liberated hydrogen (Fig. 5a-c). The increased selectivity of trans and cis-decalins, as reaction temperature increased, can be ascribed to the increased moles of hydrogen evolved as temperature increased from 250 to $350{ }^{\circ} \mathrm{C}$ (Fig. 5d). In the light of this, hydrogen partial pressure would have increased also, thereby increasing the hydrogenation of tetralin to trans and cis decalins by the available hydrogen.

\subsection{Fixed-Bed Reaction Kinetics}

A first-order rate equation was used to represent the kinetics of the dehydrogenation of tetralin at steady-state reaction condition in the fixed-bed reactor [28]. The first-order plug flow model shown in Eq. 1 was used to fit the experimental data.

$\ln (1 /(1-\mathrm{X}))=\mathrm{k}(\mathrm{W} / \mathrm{F})$,

where $\mathrm{X}$ is conversion, $\mathrm{k}$ apparent rate constant, $\mathrm{W}$ catalyst weight and $\mathrm{F}$ molar flow.

Figure 6a shows the plot of $\ln (1 /(1-\mathrm{X}))$ against $\mathrm{W} / \mathrm{F}$, and Fig. $6 \mathrm{~b}$ the Arrhenius plot. The plot fits the experimental data with approximately $0.98\left(\mathrm{R}^{2}\right)$, which means that the dehydrogenation of tetralin is apparent first-order kinetics.

As expected an increase in reaction temperature, increases the rate of tetralin dehydrogenation, which is consistent with the results shown in Fig. 5a-c. The apparent activation energy was found as $30 \mathrm{~kJ} \mathrm{~mol}^{-1}$. It is believed that a catalyst with higher activity shows lower activation energy, this means that the reaction is mass transfer limited. This is because of the large dimensions of the catalyst particles $(1.4 \mathrm{~mm} \times 1.21 \mathrm{~mm})$ and length $(5 \pm 2.1 \mathrm{~mm})$ limiting the diffusion of reactants through the pores to the catalyst active sites. Additionally, the reactor internal diameter $(20 \mathrm{~mm})$ is significantly larger than the size of the catalyst particles. An activation energy in a similar range was reported by Chen
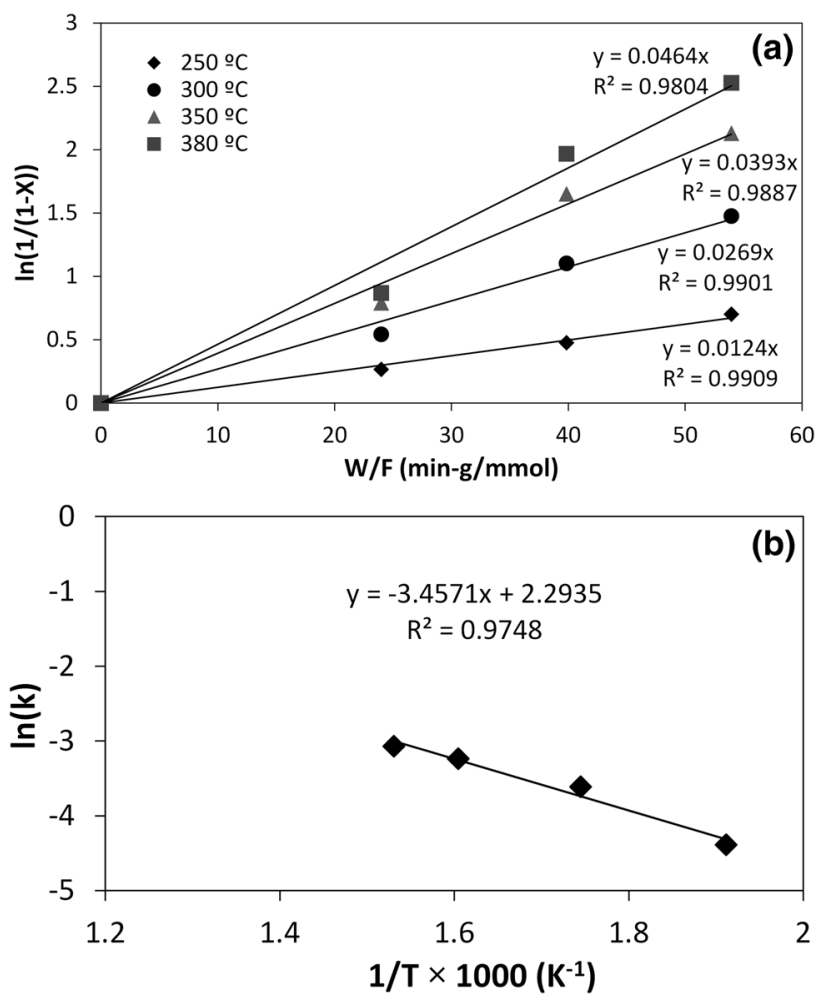

Fig. 6 Tetralin dehydrogenation using $\mathrm{Ni}-\mathrm{Mo} / \mathrm{Al}_{2} \mathrm{O}_{3}$ at $250,300,350$ and $380{ }^{\circ} \mathrm{C}$ in the fixed-bed catalytic reactor with CTSBRs 35\%, 50\% and $70 \%(\mathrm{v} / \mathrm{v})$, pressure $18 \mathrm{barg}$, LHSV $0.75 \mathrm{~h}^{-1}$, and gas flow rate of $200 \mathrm{~mL} \mathrm{~min}^{-1}\left(\mathrm{~N}_{2}\right)$ : a first-order kinetic plot using Eq. 1 and b Arrhenius equation 
et al. [20] for Mo supported on coal char as catalyst for tetralin dehydrogenation, though the rate constant was almost same, the activation energy obtained with $\mathrm{NiMo} / \mathrm{Al}_{2} \mathrm{O}_{3}$ used in this study was slightly lower.

\subsection{Coke Formation}

It is clear that high temperature is necessary to produce an appreciable amount of hydrogen through dehydrogenation of tetralin, to promote hydrogenation in downhole catalytic upgrading of heavy oil. At high temperatures, the productivity of the reaction can be constrained by catalyst deactivation due to coke deposition. Figure 7 shows the recovered catalyst TG and DTG after reaction at 250,300 and $350{ }^{\circ} \mathrm{C}$. The weight loss from 25 to $210^{\circ} \mathrm{C}$ is the vaporisation of the residual tetralin, naphthalene and $n$-hexadecane on the catalyst, while the burn-off beyond $260{ }^{\circ} \mathrm{C}$ is due to the formed coke from dehydrogenation of tetralin for $6 \mathrm{~h}$ experiment [29].

The respective coke content of the catalyst after $6 \mathrm{~h}$ of reaction was determined as $10.2 \%\left(250^{\circ} \mathrm{C}\right), 15.6 \%\left(300{ }^{\circ} \mathrm{C}\right)$ and $20.3 \%\left(350^{\circ} \mathrm{C}\right)$. This represents about $5 \%$ coke increase for every $50{ }^{\circ} \mathrm{C}$ increase in reaction temperature. This increased coke formation is the result of the increased formation of the more strongly adsorbing and more condensable naphthalene compound as reaction temperature increases (Figs. 5a-c, 6a).

In spite of the observed coke formation, when incorporated with the THAI process, tetralin can keep the asphaltenes in the heavy oil in solution, suppressing their precipitation, polymerisation and condensation to coke while they undergo cracking [16]. The use of methane gas and cyclohexane solvent as hydrogen-donors for catalytic upgrading of heavy oil in comparison to the use of a pure hydrogen gas had been reported in the literature by the authors $[16,30]$. It was found that the addition of hydrogen

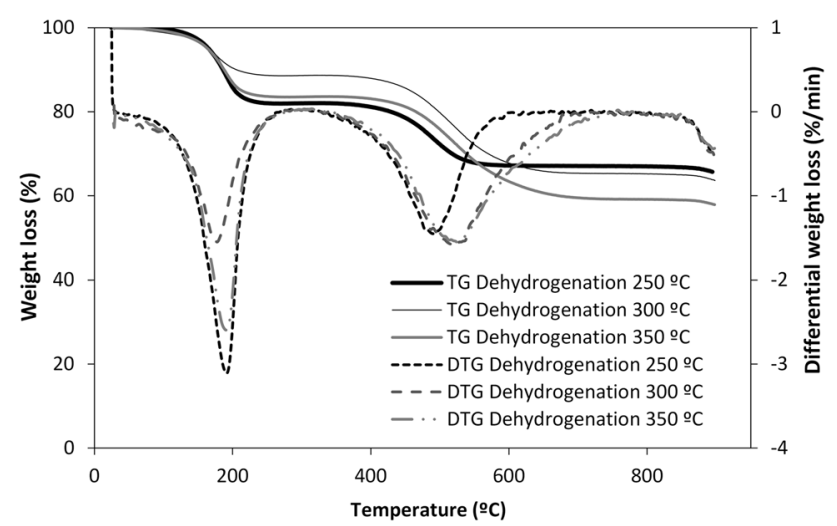

Fig. 7 TGA of the used catalyst after $6 \mathrm{~h}$ experiment at 250, 300 and $350{ }^{\circ} \mathrm{C}$ under induction heating at pressure 18 barg, LHSV $0.75 \mathrm{~h}^{-1}$, CTSBR $70 \% \mathrm{v} / \mathrm{v}$ and gas flow rate of $200 \mathrm{~mL} \mathrm{~min}^{-1}\left(\mathrm{~N}_{2}\right)$ gas improved the upgraded oil quality more than methane gas [30], while the use of cyclohexane solvent improved the upgraded oil quality more than hydrogen gas at cyclohexane/ oil ratio of 0.08 [16]. In summary, coke formation was suppressed as follows cyclohexane $>$ hydrogen gas $>$ methane gas. This is because of the ability of the produced aromatic compounds due to liberation of hydrogen gas from cyclohexane to keep the asphaltene molecules solubilized inhibiting precipitation and aggregation. Potentially, the quantity of hydrogen gas liberated from tetralin dehydrogenation (Fig. 5d) can support in situ catalytic hydroprocessing of heavy oil. Since it has been proven that the liberated hydrogen gas was beneficial in capping free radicals from cracked heavy molecules such as poly-aromatic and resins in situ and consequently halt their polymerisation and condensation into coke and increase catalyst longevity [15, 31].

\subsection{Inductive Against Conventional Heating}

\subsubsection{Catalytic Bed Temperature}

The temperature of the catalyst bed was measured during $\mathrm{IH}$ and $\mathrm{CH}$ with the aid of the thermocouple (type $\mathrm{k}$ ) inserted at its centre from the bottom. Figure 8 shows the temperature of the catalyst bed for both $\mathrm{IH}$ and $\mathrm{CH}$ when the experiment was carried out at $300{ }^{\circ} \mathrm{C}$. With $\mathrm{IH}$ the catalyst bed reached $300{ }^{\circ} \mathrm{C}$ temperatures in $16 \mathrm{~min}$ while $\mathrm{CH}$ takes $71 \mathrm{~min}$ for $70 \%$ (v/v) CTSBR. Under IH, the temperature of catalyst bed was closer to, or at, the desired temperature while for $\mathrm{CH}$ it drops in the range of $4-10{ }^{\circ} \mathrm{C}$ from the desired temperature. The average bed temperature was $299^{\circ} \mathrm{C}(\mathrm{IH})$ and $294.3{ }^{\circ} \mathrm{C}$ $(\mathrm{CH})$. Again, the fluctuation of the catalytic bed temperature between 296 and $300^{\circ} \mathrm{C}$ in the inductive heated reactor during reaction also confirms the thermocouple experience negligible heating effect in the magnetic field.

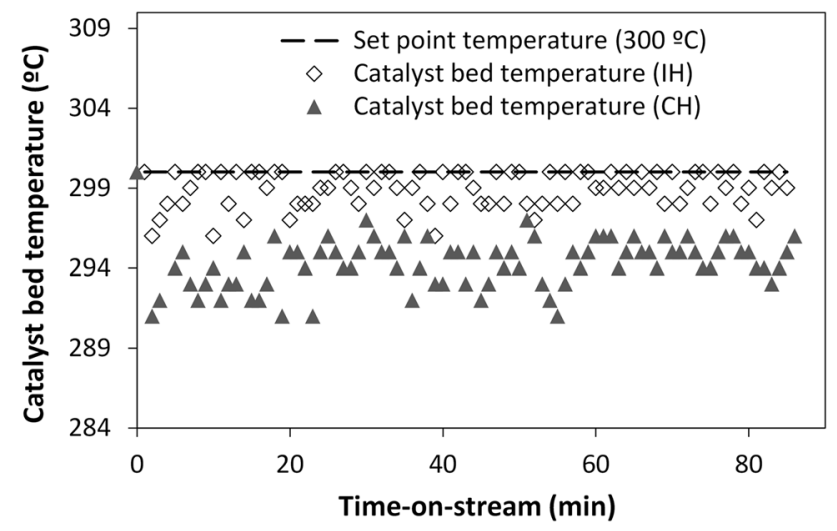

Fig. 8 Catalyst bed temperature for $\mathrm{IH}$ and $\mathrm{CH}$ at temperature $300{ }^{\circ} \mathrm{C}$, CTSBR $70 \%(\mathrm{v} / \mathrm{v})$, LHSV $0.75 \mathrm{~h}^{-1}$, pressure $18 \mathrm{barg}$ and $200 \mathrm{~mL} \mathrm{~min}^{-1}$ nitrogen flow 
Under IH, heat flows from the steel balls to the catalyst pellets and the surrounding fluid, while, with $\mathrm{CH}$ it flows from the reactor wall to the surrounding fluid and to the catalyst. The heat generated within the catalyst bed by the steel balls is rapidly transferred to the catalyst and the surrounding fluid because of their intimacy. In the light of this, the actual reaction temperature at the surface of catalyst should be about the same as the surrounding fluid. In other words, the reaction occurred nearer to, or at, the desired temperature at the surface of catalyst, whereas with $\mathrm{CH}$, heat is transferred from the surrounding fluid to the catalyst which increases the temperature gradient between the fluid and the catalyst. Hence, the temperature at the surface of the catalyst was about $5^{\circ} \mathrm{C}$ lower than the desired experimental temperature $\left(300^{\circ} \mathrm{C}\right)$.

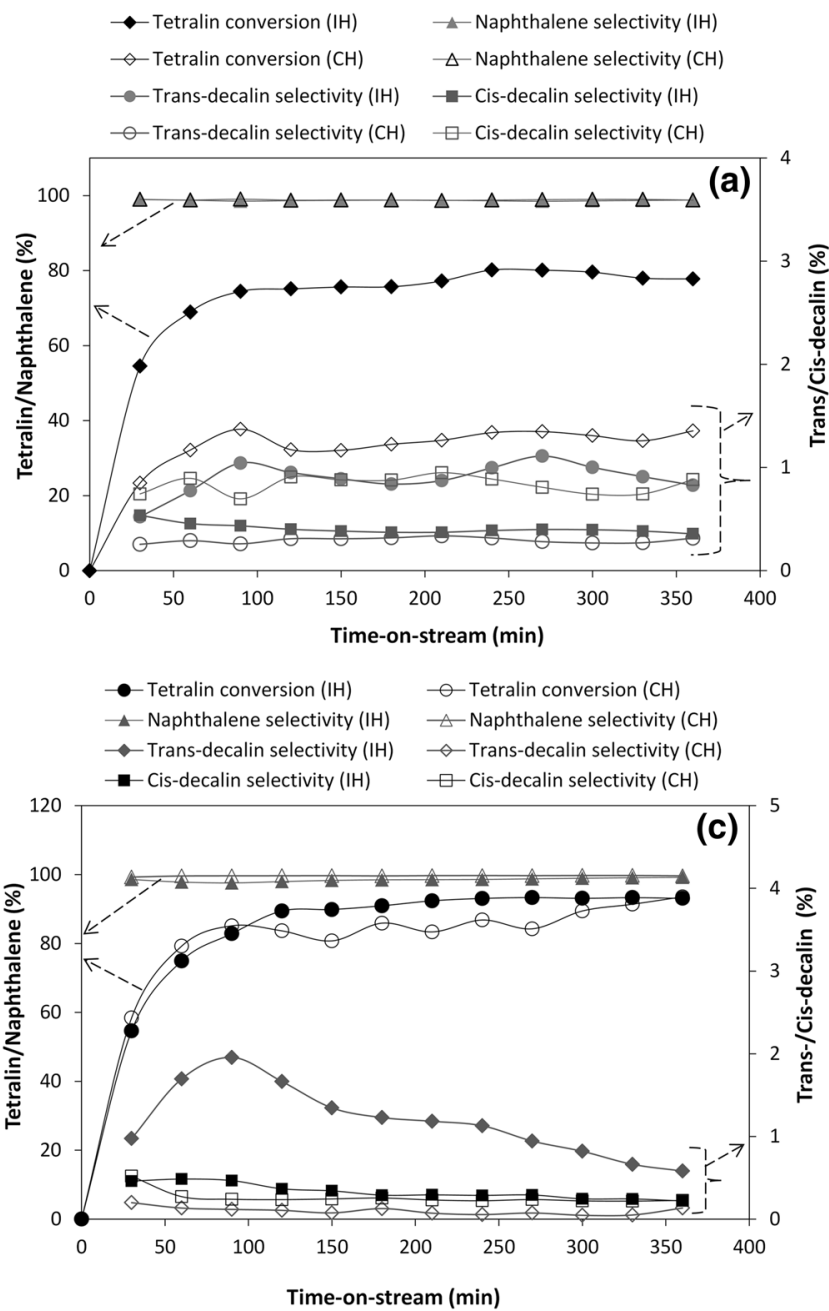

\subsubsection{Conversion, Selectivity and Liberated Hydrogen}

Figure 9 shows tetralin conversion, produced hydrogen, and selectivity for naphthalene and trans/cis-decalins using $\mathrm{IH}$ and $\mathrm{CH}$ methods at $300{ }^{\circ} \mathrm{C}, 350{ }^{\circ} \mathrm{C}$ and $380{ }^{\circ} \mathrm{C}$. All the experimental results show catalyst start up effect due to wetting and diffusion of reactants and products; hence, the conversion increases with time until steady state is achieved in the reactors. A similar observation has been previously reported in other works [29]. At the three temperatures investigated, tetralin showed superior conversion when the catalytic dehydrogenation was carried out under IH compared to $\mathrm{CH}$ method. This remarkable difference in the conversion of tetralin between IH and $\mathrm{CH}$ can be clearly observed. This suggests that the temperature between the catalyst and the surrounding fluids exert pronounced effect on the conversion of tetralin through dehydrogenation to mainly hydrogen gas and naphthalene. The dehydrogenation of tetralin under IH
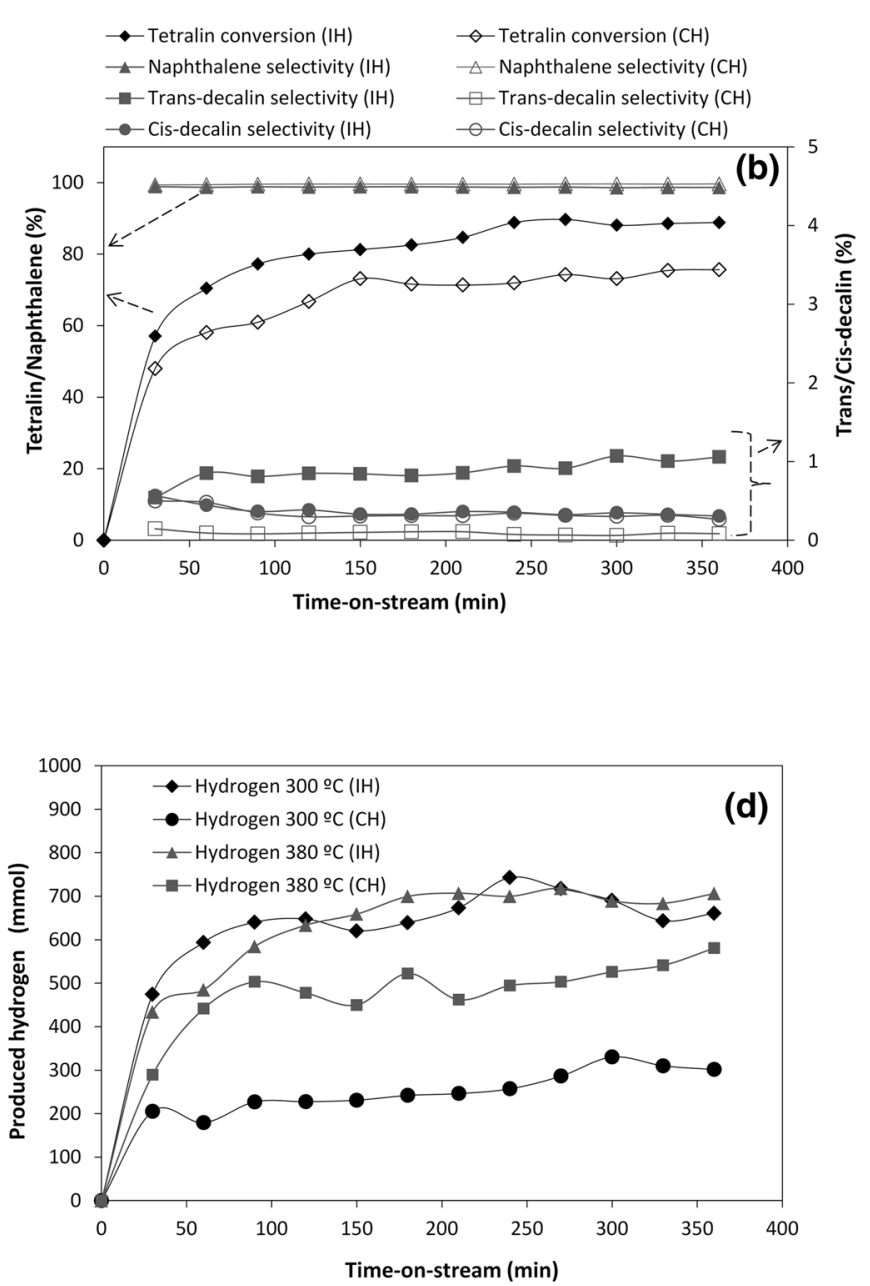

Fig. 9 Tetralin dehydrogenation conventional heating $(\mathrm{CH})$ against induction heating (IH) at a $300{ }^{\circ} \mathrm{C}$, b $350{ }^{\circ} \mathrm{C}$, c $380{ }^{\circ} \mathrm{C}$ and d produced hydrogen due to naphthalene formation at pressure $18 \mathrm{barg}$, LHSV $0.75 \mathrm{~h}^{-1}$, CTSBR $70 \% \mathrm{v} / \mathrm{v}$ and gas flow rate of $200 \mathrm{~mL} \mathrm{~min}^{-1}\left(\mathrm{~N}_{2}\right)$ 
reached $80 \%$ tetralin conversion at $300{ }^{\circ} \mathrm{C}, 88 \%$ at $350{ }^{\circ} \mathrm{C}$ and $93 \%$ at $380{ }^{\circ} \mathrm{C}$, whereas at the same conditions the reaction under $\mathrm{CH}$ achieved $37 \%\left(300{ }^{\circ} \mathrm{C}\right), 73 \%\left(350{ }^{\circ} \mathrm{C}\right)$ and $86 \%\left(380{ }^{\circ} \mathrm{C}\right)$ respectively (Fig. $\left.9 \mathrm{a}-\mathrm{c}\right)$. Although, the $\mathrm{IH}$ showed superior tetralin conversion, the difference in tetralin conversion under $\mathrm{IH}$ and $\mathrm{CH}$ decreases as the reaction temperature increases from 300 to $380{ }^{\circ} \mathrm{C}$. The results show that to achieve comparable tetralin conversions, the $\mathrm{CH}$ reaction needs to be operated at $50{ }^{\circ} \mathrm{C}$ or higher temperature than that of the IH. Hence, the conventionally-heated showed similar tetralin conversion at 300 and $380{ }^{\circ} \mathrm{C}$ to that achieved with $\mathrm{IH}$ at 250 and $300^{\circ} \mathrm{C}$ (Figs. 5a, b, 9a, c).

Converse to the above trends, no significant difference was observed for naphthalene selectivity under $\mathrm{IH}$ and $\mathrm{CH}$ methods, selectivity greater than $98 \%$ was achieved for all the investigated temperatures. Under IH, a thermally stable trans-decalin was produced more than unstable cis-decalin while under $\mathrm{CH}$ more $c i s$-decalin was produced. This can be attributed to the difference in temperature at the surface of the catalyst and the activity induced by the heating technique. At $300^{\circ} \mathrm{C}$, the selectivity of trans and cis-decalins under $\mathrm{CH}$ and $\mathrm{IH}$ were mirror opposite. Whilst at 350 and $380{ }^{\circ} \mathrm{C}$ the selectivity of $\mathrm{cis}$-decalin was approximately the same for $\mathrm{CH}$ and IH. However, more hydrogen was liberated from tetralin when the reaction was carried out under IH than $\mathrm{CH}$ (Fig. 9c).

Thermodynamically, a system that generates heat from within favours tetralin conversion and hydrogen evolution due to dehydrogenation, compared with a system in which the catalyst bed function as a heat sink (Fig. 8). The activity of the catalyst under IH would have been enhanced in addition to the thin temperature gradient between the catalyst and the surrounding fluid. Polarization of reactant molecules, improved catalyst activity, and enhanced molecular diffusion or transport of species in the reaction medium have been proposed as some of the non-thermal effects of electromagnetic field on heterogeneous catalysis carried out under inductive or microwave heating [22]. These non-thermal effects could have improved the activity of the catalyst under IH. The closeness of the steel balls to the catalyst pellets induced rapid heat transfer in the inductive heated catalytic bed which would have promoted faster products (naphthalene, trans and cis decalins) desorption from the catalyst active sites and lower the strong adsorptive energy of naphthalene $[22,32]$. This condition could have increased conversion of tetralin and dehydrogenation under $\mathrm{IH}$. Hence, the low tetralin conversion observed under $\mathrm{CH}$ can be attributed to the effect of slow desorption of produced naphthalene from the catalyst surface due to the large temperature gradient between the catalyst and the surrounding fluid (Fig. 8). This could have created heat and mass transfer effect which decrease the catalyst activity under $\mathrm{CH}$ [32]. In the case of $\mathrm{IH}$ with steel balls, the steel balls rapidly transfer heat to the surface of the catalyst and the bulk solvent whereas in $\mathrm{CH}$ heat transfer from the bulk solvent to the catalyst is slow (Fig. 8). Hence, under IH naphthalene desorption from the catalyst active sites is enhanced and the strong adsorptive energy of aromatic hydrocarbons lowered [22].

\subsubsection{First-Order Kinetic Plot}

Figure 10 shows the plot of $\ln (1 /(1-\mathrm{X}))$ against $\mathrm{W} / \mathrm{F}$ for $\mathrm{IH}$ and $\mathrm{CH}$ systems. The rate constants under $\mathrm{IH}$ were higher than those of conventional system at the same reaction temperature, which means the dehydrogenation rate is higher with inductive than $\mathrm{CH}$. This is in agreement with the observation shown in Fig. 9, which affirms that the rate of reaction is higher under $\mathrm{IH}$ than $\mathrm{CH}$.

Due to the lower temperatures experienced at the catalyst surface with $\mathrm{CH}$ system (i.e., the actual temperature in the catalyst bed is lower than the experimental temperature as shown in Fig. 8), the kinetics are slower compared to that observed with IH. Additionally, the activity of the catalyst could have been limited by adsorbed naphthalene product under $\mathrm{CH}$. The rate constant under $\mathrm{CH}$ at $350{ }^{\circ} \mathrm{C}$ $\left(\sim 0.020 \mathrm{~min}^{-1}\right)$ is closely comparable to $0.027 \mathrm{~min}^{-1}$ obtained under $\mathrm{IH}$ at $300{ }^{\circ} \mathrm{C}$ (Fig. 6a), which is in agreement with tetralin conversion results shown in Fig. $5 \mathrm{~b}$ (IH at $\left.300{ }^{\circ} \mathrm{C}\right)$ and Fig. $9 \mathrm{~b}\left(\mathrm{CH}\right.$ at $\left.350^{\circ} \mathrm{C}\right)$.

Figure 11 shows the TGA of the catalyst after reaction under $\mathrm{CH}$ for $300-380{ }^{\circ} \mathrm{C}$. The coke content of the catalyst after $6 \mathrm{~h}$ of experiments is as follows: $8.2 \%\left(300^{\circ} \mathrm{C}\right), 13.6 \%$ $\left(350{ }^{\circ} \mathrm{C}\right)$ and $16.4 \%\left(380^{\circ} \mathrm{C}\right)$. Compared to $\mathrm{IH}$, coke formation was lesser because the amount of condensed naphthalene product under $\mathrm{CH}$ is lower than that produced under $\mathrm{IH}$ at the same experimental conditions. Additionally, the improved catalytic activity as well as increased rate of reaction under IH could have also contributed to the high coke formation observed.

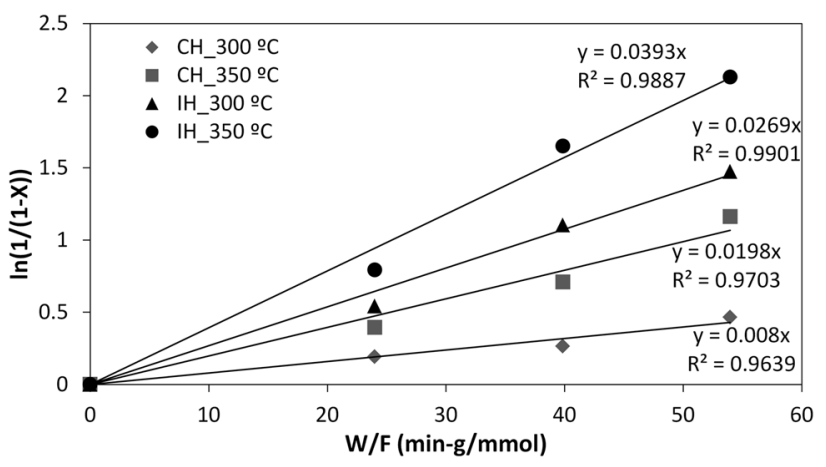

Fig. 10 First-order kinetic plot using Eq. 1 for $\mathrm{IH}$ and $\mathrm{CH}$ at 300 and $350{ }^{\circ} \mathrm{C}$ at pressure $18 \mathrm{barg}$, LHSV $0.75 \mathrm{~h}^{-1}$, CTSBR $70 \% \mathrm{v} / \mathrm{v}$ and gas flow rate of $200 \mathrm{~mL} \mathrm{~min}^{-1}\left(\mathrm{~N}_{2}\right)$ 


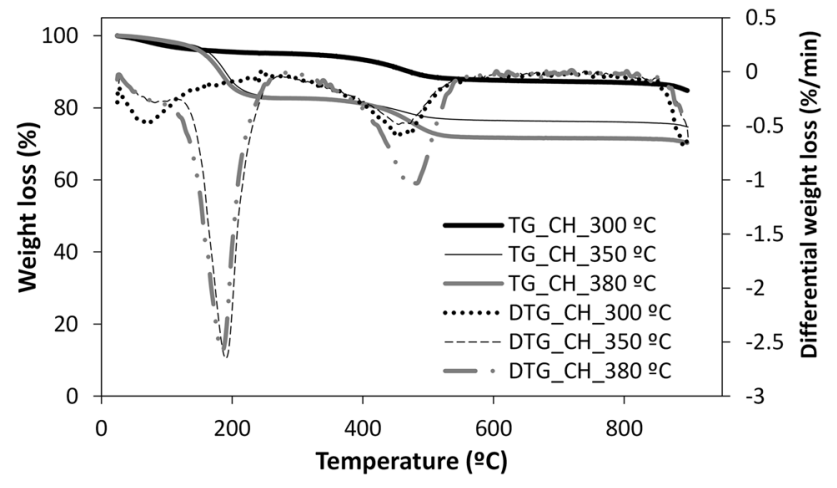

Fig. 11 TGA of the used catalyst after $6 \mathrm{~h}$ experiment at 300, 350 and $380{ }^{\circ} \mathrm{C}$ under conventional heating at pressure $18 \mathrm{barg}$, LHSV $0.75 \mathrm{~h}^{-1}$, CTSBR $70 \% \mathrm{v} / \mathrm{v}$ and gas flow rate of $200 \mathrm{~mL} \mathrm{~min}^{-1}\left(\mathrm{~N}_{2}\right)$

\section{Conclusion}

Tetralin dehydrogenation as a hydrogen source for underground catalytic upgrading of heavy oil was studied in a fixed-bed reactor that mimics the catalyst packing around the horizontal production well (CAPRI) of the THAI process under induction heating at $300-380{ }^{\circ} \mathrm{C}, 18 \mathrm{bar}, 0.75 \mathrm{~h}^{-1}$ and $70 \%(\mathrm{v} / \mathrm{v})$ CTSBR using $\mathrm{NiMo} / \mathrm{Al}_{2} \mathrm{O}_{3}$ catalyst. The results were compared to those achieved under $\mathrm{CH}$. It was found that under the same operating conditions, higher tetralin conversion and more hydrogen liberation was observed in the inductive-heated system compared with those achieved with the conventional system. Additionally, the catalyst benefited from enhanced activity under the IH because of the non-thermal effect of the eddy current and magnetic fields. The temperature gradient between the surrounding fluid and catalyst was larger under conventional-heated system than inductive-heated counterpart. At $350{ }^{\circ} \mathrm{C}$ about $88 \%$ tetralin conversion was observed, $0.605 \mathrm{~mol}$ of tetralin produced about $0.876 \mathrm{~mol}$ of hydrogen mainly through dehydrogenation to naphthalene. This liberated hydrogen has the potential to promote hydroprocessing reactions when combined with in situ catalytic upgrading of heavy oil provided the partial pressure of hydrogen is favourable.

Acknowledgements The authors acknowledge, with thanks, funding from Engineering and Physical Science Research Council (EPSRC), United Kingdom with Grant Number EP/N032985/1. Data in this paper is available free of charge via https://edata.bham.ac.uk/.

\section{Compliance with Ethical Standards}

Conflict of interest The authors declare no conflict of interest.

Ethical Approval This paper has been prepared in compliance with Ethical Standards. The corresponding author confirms this paper conforms to ethical standards and the project from which it is derived was granted ethical approval from the University of Birmingham. No humans or animals were used in the course of this research.
Informed Consent The corresponding author has the informed consent of all co-authors in submitting this paper.

Open Access This article is distributed under the terms of the Creative Commons Attribution 4.0 International License (http://creativeco mmons.org/licenses/by/4.0/), which permits unrestricted use, distribution, and reproduction in any medium, provided you give appropriate credit to the original author(s) and the source, provide a link to the Creative Commons license, and indicate if changes were made.

\section{References}

1. EIA (2017) Global transportation energy consumption: examination of scenarios to 2040 using ITEDD. https://www.eia.gov/analy sis/studies/transportation/scenarios/pdf/globaltransportation.pdf. Accessed 06/02/2019

2. Shah A, Fishwick RP, Leeke GA, Wood J, Rigby SP, Greaves M (2011) Experimental optimization of catalytic process in situ for heavy-oil and bitumen upgrading. J Can Petrol Technol 50:33-47

3. Hart A, Shah A, Leeke G, Greaves M, Wood J (2013) Optimization of the CAPRI process for heavy oil upgrading: effect of hydrogen and guard bed. Ind Eng Chem Res 52:15394-15406

4. Ayasse C, Greaves M, Turta A (2002) Oilfield in situ hydrocarbon upgrading process. US Patent 6412557 B1

5. Petrobank Energy and Resources Ltd. (2007) Strength in heavy oil: growing THAI ${ }^{\mathrm{TM}}$ globally. online:https://www.knotia.ca/kstor e/productinfo/fric08/PDFs/Petrobank\%20Energy\%20and\%20Res ources\%20Ltd.\%20AR_2007.pdf. Accessed 29 Feb 2018

6. Rabiu Ado M, Greaves M, Rigby SP (2017) Dynamic simulation of the Toe-to-Heel Air Injection heavy oil recovery process. Energy Fuels 31:1276-1284

7. Hart A, Wood J, Greaves M (2017) In situ catalytic upgrading of heavy oil using a pelletized $\mathrm{Ni}-\mathrm{Mo} / \mathrm{Al}_{2} \mathrm{O}_{3}$ catalyst in the THAI process. J Pet Sci Eng 156:958-965

8. Xia TX, Greaves M (2001) 3-D physical model studies of downhole catalytic upgrading of Wolf Lake heavy oil using THAI. In: Paper 2001-17 presented at the Petroleum Society's Canadian international petroleum conference 2001, Calgary, Alberta, Canada, 12-14 June

9. Ceylan S, Friese C, Lammel C, Mazac K, Kirschning A (2008) Inductive heating for organic synthesis by using functionalized magnetic nanoparticles inside microreactors. Angew Chem Int Ed 47:8950-8953

10. Idakiev VV, Marx S, Roßau A, Bück A, Tsotsas E, Mörl L (2015) Inductive heating of fluidized beds: influence on fluidization behaviour. Powder Technol 286:90-97

11. Sadeghi A, Hassanzadeh H, Harding TG (2017) Modeling of desiccated zone development during electromagnetic heating of oil sands. J Pet Sci Eng 154:163-171. https://doi.org/10.1016/j.petro 1.2017.04.033

12. Zadražil A, Štěpánek F (2015) Remote control of reaction rate by radiofrequency heating of composite catalyst pellets. Chem Eng Sci 134:721-726. https://doi.org/10.1016/j.ces.2015.05.055

13. Varsano F, Bellusci M, Provino A, Petrecca M (2018) NiCo as catalyst for magnetically induced dry reforming of methane. Mater Sci Eng 323:012005. https://doi.org/10.1088/1757899x/323/1/012005

14. Alemán-Vázquez LO, Cano-Domínguez JL, García-Gutiérrez JL (2012) Effect of tetralin, decalin and naphthalene as hydrogen donors in the upgrading of heavy oils. Procedia Eng 42:532-539 
15. Hart A, Wood J (2018) In situ catalytic upgrading of heavy crude with CAPRI: influence of hydrogen on catalyst pore plugging and deactivation due to coke. Energies 11:636

16. Hart A, Lewis C, White T, Greaves M, Wood J (2015) Effect of cyclohexane as hydrogen-donor in ultradispersed catalytic upgrading of heavy oil. Fuel Process Technol 138:724-733

17. Carlson CS, Langer AW, Stewart J, Hill RM (1958) Thermal hydrogenation. Transfer of hydrogen from tetralin to cracked residua. Ind Eng Chem 50:1067-1070

18. Park H-B, Kim K-D, Lee Y-K (2018) Promoting asphaltene conversion by tetralin for hydrocracking of petroleum pitch. Fuel 222:105-113

19. Wang Y, Shah N, Huggins FE, Huffman GP (2006) Hydrogen production by catalytic dehydrogenation of tetralin and decalin over stacked cone carbon nanotube-supported Pt catalysts. Energy Fuels 20:2612-2615

20. Chen Z, Xie J, Liu Q, Wang H, Gao S, Shi L, Liu Z (2019) Characterization of direct coal liquefaction catalysts by their sulfidation behavior and tetralin dehydrogenation activity. J Energy Inst 92:1213-1222. https://doi.org/10.1016/j.joei.2018.05.009

21. Jiang N, Rama Rao KS, Jin M-J, Park S-E (2012) Effect of hydrogen spillover in decalin dehydrogenation over supported Pt catalysts. Appl Catal A 425-426:62-67

22. Suttisawat Y, Sakai H, Abe M, Rangsunvigit P, Horikoshi S (2012) Microwave effect in the dehydrogenation of tetralin and decalin with a fixed-bed reactor. Int J Hydrog Energy 37:3242-3250

23. Kim K, Oh J, Kim TW, Park JH, Han JW, Suh Y-W (2017) Different catalytic behaviors of Pd and Pt metals in decalin dehydrogenation to naphthalene. Catal Sci Technol 7:3728-3735

24. Liu H, Meng X, Zhao D, Li Y (2008) The effect of sulfur compound on the hydrogenation of tetralin over a Pd-Pt/HDAY catalyst. Chem Eng J 140:424-431
25. Hart A, Omajali JB, Murray AJ, Macaskie LE, Greaves M, Wood $\mathrm{J}$ (2016) Comparison of the effects of dispersed noble metal (Pd) biomass supported catalysts with typical hydrogenation $(\mathrm{Pd} / \mathrm{C}$, $\left.\mathrm{Pd} / \mathrm{Al}_{2} \mathrm{O}_{3}\right)$ and hydrotreatment catalysts $\left(\mathrm{CoMo} / \mathrm{Al}_{2} \mathrm{O}_{3}\right)$ for in situ heavy oil upgrading with Toe-to-Heel Air Injection (THAI). Fuel 180:367-376

26. Smalcerz A, Przylucki R (2013) Impact of electromagnetic field upon temperature measurement of induction heated charges. Int J Thermophys 34:667-679

27. Henkel C, Muley DP, Abdollahi KK, Marculescu C, Boldor D (2016) Pyrolysis of energy cane bagasse and invasive Chinese tallow tree (Triadica sebifera L.) biomass in an inductively heated reactor. Energy Convers Manag 109:175-183

28. Williams MF, Fonfe B, Woltz C, Jentys A, Van Veen JAR, Lercher JA (2007) Hydrogenation of tetralin on silica-alumina-supported $\mathrm{Pt}$ catalysts II. Influence of the support on catalytic activity. J Catal 251:497-506

29. Hassan F, Al-Duri B, Wood J (2012) Effect of supercritical conditions upon catalyst deactivation in the hydrogenation of naphthalene. Chem Eng J 207-208:133-141

30. Hart A, Leeke G, Greaves M, Wood J (2014) Downhole heavy crude oil upgrading by CAPRI: effect of hydrogen and methane gases upon upgrading and coke formation. Fuel 119:226-235

31. Siddiquee MN, de Klerk A (2019) Heteroatom removal as pretreatment of boiler fuels. Energy Fuels. https://doi.org/10.1021/ acs.energyfuels.8b04044

32. Suttisawat Y, Horikoshi S, Sakai H, Abe M (2010) Hydrogen production from tetralin over microwave-accelerated Pt-supported activated carbon. Int J Hydrog Energy 35:6179-6183

Publisher's Note Springer Nature remains neutral with regard to jurisdictional claims in published maps and institutional affiliations. 